\title{
The Arctic Front and its variability in the Norwegian Sea
}

\author{
Roshin P. Raj ${ }^{1}$, Sourav Chatterjee ${ }^{2}$, Laurent Bertino ${ }^{1}$, Antonio Turiel ${ }^{3}$, and Marcos Portabella ${ }^{3}$ \\ ${ }^{1}$ Nansen Environmental and Remote Sensing Center, Bjerknes Centre for Climate Research, \\ Thormøhlens gate 47, Bergen, Norway \\ ${ }^{2}$ National Centre for Polar and Ocean Research, Goa, India \\ ${ }^{3}$ Barcelona Expert Centre, Institute of Marine Sciences (ICM-CSIC), Barcelona, Spain
}

Correspondence: Roshin P. Raj (roshin.raj@nersc.no)

Received: 25 December 2018 - Discussion started: 22 January 2019

Revised: 21 October 2019 - Accepted: 6 November 2019 - Published: 16 December 2019

\begin{abstract}
The Arctic Front (AF) in the Norwegian Sea is an important biologically productive region which is wellknown for its large feeding schools of pelagic fish. A suite of satellite data, a regional coupled ocean-sea ice data assimilation system (the TOPAZ reanalysis) and atmospheric reanalysis data are used to investigate the variability in the lateral and vertical structure of the AF. A method, known as "singularity analysis", is applied on the satellite and reanalysis data for 2-D spatial analysis of the front, whereas for the vertical structure, a horizontal gradient method is used. We present new evidence of active air-sea interaction along the AF due to enhanced momentum mixing near the frontal region. The frontal structure of the AF is found to be most distinct near the Faroe Current in the south-west Norwegian Sea and along the Mohn Ridge. Coincidentally, these are the two locations along the AF where the air-sea interactions are most intense. This study investigates in particular the frontal structure and its variability along the Mohn Ridge. The seasonal variability in the strength of the AF is found to be limited to the surface. The study also provides new insights into the influence of the three dominant modes of the Norwegian Sea atmospheric circulation on the AF along the Mohn Ridge. The analyses show a weakened AF during the negative phase of the North Atlantic Oscillation (NAO-), even though the geographical location of the front does not vary. The weakening of AF during NAO - is attributed to the variability in the strength of the Norwegian Atlantic Front Current over the Mohn Ridge associated with the changes in the wind field.
\end{abstract}

\section{Introduction}

Ocean fronts are boundaries between distinct water masses with large gradients in temperature or salinity (e.g. Bakun, 1996; D’Asaro et al., 2011). The Arctic Front (AF; Swift and Aagaard, 1981; Piechura and Walczowski, 1995) is one of the most prominent ocean fronts in the Norwegian Sea. Similar to its counterparts in the world ocean, the AF is an important biologically productive region also known for its large feeding schools of pelagic fish (e.g. Holst et al., 2004; Blindheim and Rey, 2004; Melle et al., 2004). On its influence on higher trophic levels, it is important to note that Jan Mayen Island located near the $\mathrm{AF}$ is an important breeding region inhabited by large colonies of seabirds (Norway Ministry of Environment, 2008-2009).

The AF in the Norwegian Sea extends from the IcelandFaroe Plateau to the Mohn-Knipovich Ridge (Nilsen and Nilsen, 2007) and is associated with the interaction of the warm and saline Atlantic Water and the cold and fresher Arctic Water (Blindheim and Ådlandsvik, 1995). As shown in Fig. 1, the Atlantic Water is carried into the Norwegian Sea via the Norwegian Atlantic Current (e.g. Orvik et al., 2001; Raj et al., 2016), which is a two-branch current system, with an eastern branch following the shelf edge as a barotropic slope current, and a western branch following the western rim of the Norwegian Sea as a topographically guided front current (Poulain et al., 1996; Orvik and Niiler, 2002; Skagseth and Orvik, 2002; Orvik and Skagseth, 2003). These two branches are known as the Norwegian Atlantic Slope Current (NwASC; Skagseth and Orvik, 2002) and the Norwegian Atlantic Front Current (NwAFC; Mork and Skagseth, 2010) respectively. On its poleward journey, 


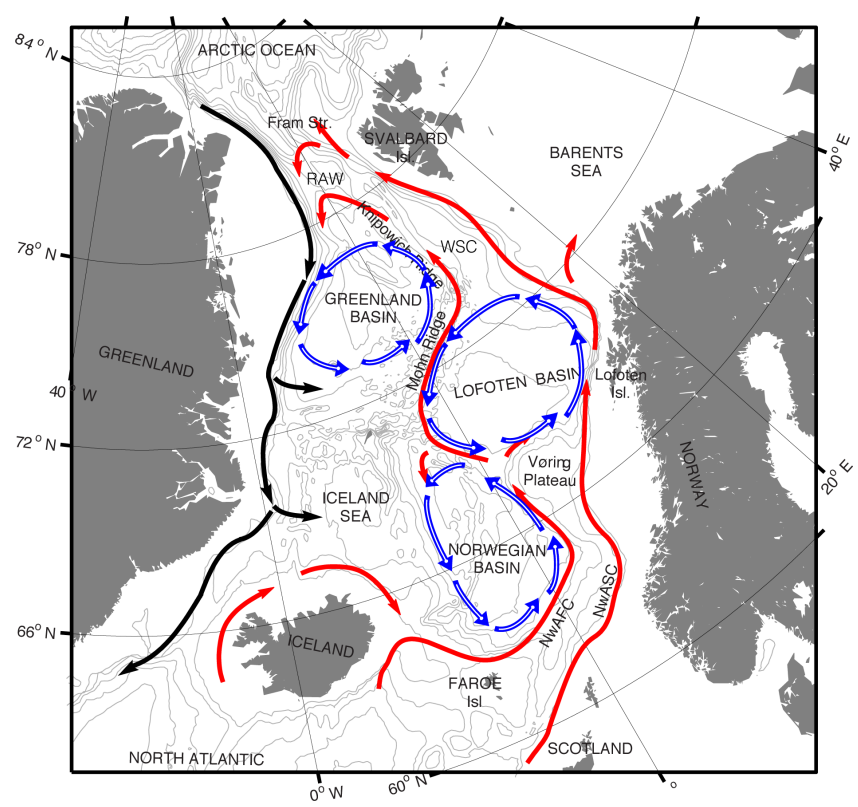

Figure 1. The Nordic Seas with schematic water pathways showing the northward flowing Atlantic Water in the surface (red) and southward flowing East Greenland Current (black). The two branches of the Norwegian Atlantic Current, the Norwegian Atlantic slope current (NwASC) and Norwegian Atlantic front current (NwAFC) are represented by red arrows. The cyclonic gyre circulations in the Norwegian Basin, Lofoten Basin and Greenland Basin are indicated in blue. See Chatterjee et al. (2018) and Raj et al. (2015) for details. Grey isobaths are drawn for every $600 \mathrm{~m}$. The location of the Arctic Front in the Norwegian Sea coincides with the location of the NwAFC.

the NwASC bifurcates, one part flowing into the Barents Sea and the other continuing towards the Fram Strait as the core of the West Spitsbergen Current (Helland-Hansen and Nansen, 1909; Aagaard et al., 1985). The NwAFC on its way to the north encounters three deep currents (Fig. 1); one over the Mohn Ridge flows in the opposite direction (Orvik, 2004). The NwAFC continues poleward, topographically guided by the Mohn Ridge and the Knipovich Ridge, as the western branch of the West Spitsbergen Current (WSC; Walczowski and Piechura, 2006). The Atlantic Water carried by the western branch of the West Spitsbergen Current recirculates mostly within the Nordic Seas, as the Return Atlantic Water (RAW; Eldevik et al., 2009). This AW mixes with the Polar Waters transported south from the Arctic by the East Greenland Current and forms the hydrographically distinct Arctic Water (Blindheim and Østerhus, 2005). The further interaction of the Arctic Water with warm and saline Atlantic Water results in the AF (Swift, 1986). The location of the AF follows the topography and coincides with the location where Arctic Water meets the Atlantic Water.

The AF has been subject of many studies (e.g. Piechura and Walczowski, 1995; Nilsen and Nilsen, 2007). However, the impact of the large-scale atmospheric forcing on the spa- tial (lateral) and vertical variability of the front has not yet been described. Our study aims to examine the structure (lateral and vertical) of the AF using satellite and reanalysis data, on climatological-mean and seasonal-mean timescales (1991-2015). The near-permanent structure of the AF justifies its investigation over long timescales. In addition, the study aims to examine the influence of the three dominant modes of the large-scale atmospheric forcing in the Norwegian Sea, i.e. the North Atlantic Oscillation (NAO), the East Atlantic Pattern (EAP) and the Scandinavian Pattern (SCAN), on the variability of the AF. The NAO is the most dominant atmospheric mode in the North Atlantic and Nordic Seas (Fig. 2). Even though the impact of the NAO on the NwASC is well-known, its impact on the NwAFC and on the AF is not clearly documented. Furthermore, it has been reported that the location of the centres of the NAO dipole can be affected through the interplay with EAP and SCAN teleconnection patterns (e.g. Moore et al., 2012; Chafik et al., 2017). The independent effect of EAP and SCAN on the AF has also been not investigated yet. We perform a composite analysis (see Sect. 2) on the monthly ocean and atmospheric reanalysis data in order to capture the variability and thus to delineate the impact of the three main atmospheric modes of the Norwegian Sea on the AF. In Sect. 2, we describe the different data sets and methods used in this study. The results are presented in Sect. 3 and are discussed and summarised in Sect. 4.

\section{Data}

\subsection{TOPAZ reanalysis data}

TOPAZ is a coupled ocean and sea ice data assimilation system for the North Atlantic and the Arctic that is based on the Hybrid Coordinate Ocean Model (HYCOM) and the ensemble Kalman filter data assimilation, the results of its fourth version (TOPAZ4) have been extensively validated (e.g. Lien et al., 2016; Xie et al., 2017; Chatterjee et al., 2018). The ocean model in TOPAZ4 is an eddy-permitting model with 28 hybrid z-isopycnal layers at a horizontal resolution of 12 to $16 \mathrm{~km}$ in the Nordic Seas and the Arctic. TOPAZ4 represents the Arctic component of the Copernicus Marine Environment Monitoring Service (CMEMS) and is forced by the European Centre for Medium-Range Weather Forecasts (ECMWF) Reanalysis (ERA Interim) and assimilates measurements including along-track altimetry data, sea surface temperatures, sea ice concentrations and sea ice drift from satellites along with in situ temperature and salinity profiles. The monthly TOPAZ4 results used in this study for the time period 1991-2015 have been obtained via CMEMS (http://marine.copernicus.eu/, last access: November 2018). 

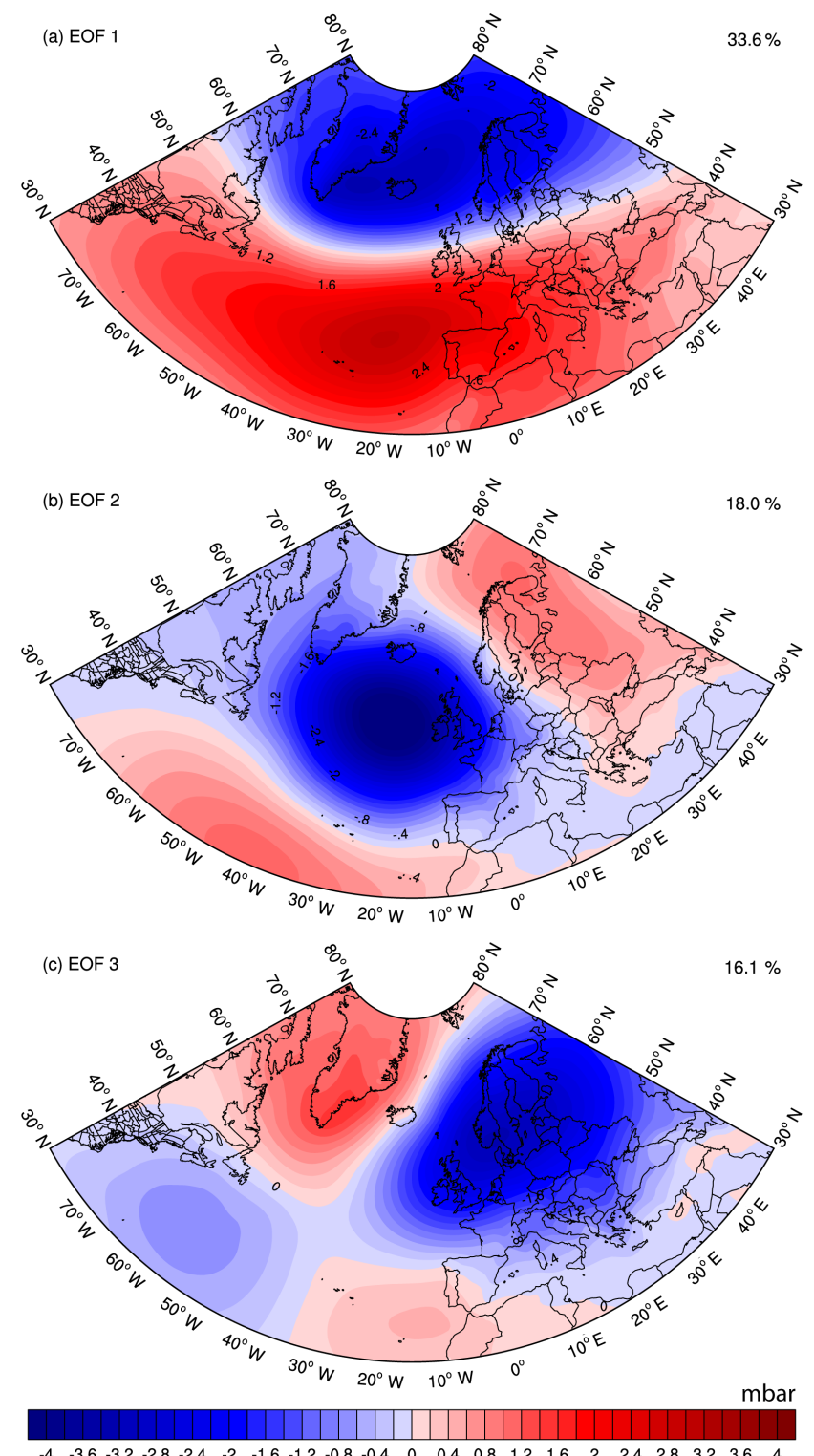

Figure 2. The first three EOF modes of deseasoned and detrended ERA Interim MSLP (1991-2015) multiplied by the standard deviation of the corresponding principle components. The number in the top right corner of each panel indicates the percentage of variance explained.

\subsection{Satellite and atmospheric reanalysis data}

Advanced Microwave Scanning Radiometer (AMSRE; 2002-2011; $0.25^{\circ}$ grid) SST and QuikSCat winds (1999$2009 ; 0.25^{\circ}$ grid) are the satellite data sets used in this study. These monthly gridded data sets are obtained from http://apdrc.soest.hawaii.edu/ (last access: July 2018). For the analysis using satellite data, this study only uses the data from the overlapping time period of AMSRE and QuikSCat, i.e. 8 years (2002-2009). In addition, monthly outputs (winds and mean sea level pressure (MSLP); $0.25^{\circ}$ grid) from the
ECMWF ERA Interim (Dee et al., 2011), which also assimilates the above-mentioned satellite data sets during the above-mentioned coincident periods, are used in this study over a longer time period, i.e. 1991-2015.

\section{Methods}

\subsection{EOF analysis}

The monthly detrended and deseasoned ERA Interim MSLP data are used to calculate the three leading empirical orthogonal functions (EOFs) of atmospheric variability in the North Atlantic $\left(80^{\circ} \mathrm{W}\right.$ to $50^{\circ} \mathrm{E}$ and 30 to $\left.80^{\circ} \mathrm{N}\right)$, which are based on singular value decomposition, according to the method described by Hannachi et al. (2007). The data are weighted by the cosine of their latitude at every grid point of the study region to account for decreasing grid sizes towards the pole. The three leading modes of atmospheric variability in the North Atlantic are the North Atlantic Oscillation (NAO), the East Atlantic Pattern (EAP) and the Scandinavian Pattern (SCAN). These three EOFs explain respectively $34 \%, 18 \%$ and $16 \%$ of the MSLP variability over the North Atlantic (Fig. 2). Even though EAP and SCAN individually explain less than $20 \%$ of MSLP variability (EAP: $18 \%$; SCAN: $16 \%$ ), several studies found that its effect on the Nordic Seas cannot be neglected (Comas-Bru and McDermott, 2013; Chafik et al., 2017). The total variance (68\%) explained by the three modes estimated in our study is comparable to those computed in earlier studies using the NCEP data (60\%; Chafik et al., 2017). Standardised principle components of the three modes are used as indices for NAO, EAP and SCAN respectively (Fig. S1 in the Supplement).

\subsection{Composite analysis}

For composite analysis, the positive/negative phase of the $\mathrm{NAO}(\mathrm{NAO}+/ \mathrm{NAO}-)$ are categorised as those months with NAO index values (Sect. 3.1) above/below one standard deviation calculated over the entire period from 1991 to 2015 . Similarly, the positive/negative phase of EAP and SCAN are estimated from their respective time series (Fig. S1). The significance of difference in the composite mean and climatological mean is estimated using the two-sample $t$ test for equal means (Snedecor and Cochran, 1989).

\subsection{Singularity analysis}

There are several methods used in previous studies to identify ocean fronts from satellite data (e.g. Cayula and Cornillon, 1992, 1995; Garcia-Olivares et al., 2007; Turiel et al., 2008). One of them is singularity analysis, which has been established as a powerful tool to detect frontal structures and streamlines from satellite images (Turiel et al., 2008, 2009; Portabella et al., 2012; Lin et al., 2014; Umbert et al., 2015). In 1992, Mallat and Huang introduced singularity analysis of 
scalar variables in the context of wavelet analysis. Singularity analysis aims to obtain a dimensionless measure known as the singularity exponent at each point, which represents the degree of irregularity at that location. Singularity exponents are dimensionless and can be derived from any scalar quantity, e.g. SST (Turiel et al., 2009) and wind components (Portabella et al., 2012; Lin et al., 2014). A singularity exponent is a continuous extension of classical concepts such as continuity or differentiability. The main difference between the maximum gradient method and singularity exponents is that singularity exponents are normalised so that the absolute value of the gradient is irrelevant. What is important is the degree of correlation between nearby gradients: singularity exponents are the dimensionless measures of that correlation. Hence the results from the singularity analysis of different scalar variables (for, e.g. SST and wind speed) can be directly compared. Furthermore, singularity analysis does not require knowledge of the velocity field, because it is a Eulerian method exploiting the scaling properties of the spatial correlations of the gradients of a given scalar field. Thus, singularity analysis has an advantage over the use of Lyapunov exponents (Garcia-Olivares et al., 2007), another widely used methodology which requires the velocity field to be known.

Our study uses singularity analysis to detect the AF in the Norwegian Sea from satellite data (SST and wind speed) as well as from ocean reanalysis data (temperature). Singularity exponents of the above scalar variables have been estimated using an online service provided by the Barcelona Expert Center (http://bec.icm.csic.es/CP34GUIWeb, last access: October 2018). The online toolbox first evaluates the modulus of the gradient of the scalar at each point in the specified domain, i.e. the Norwegian Sea in our study. A wavelet projection is applied on the modulus of the gradient of the variable as it has been shown to be useful to remove longrange correlations and thus reveal the actual local behaviour of the function (Turiel et al., 2008). Then a log-log regression of the wavelet projection versus the resolution scale is used to determine the scaling properties of the gradient correlations, and the slope of such a regression is precisely the singularity exponent. Therefore, singularity analysis assigns a singularity exponent to each point in an image. The singularity exponent value provides information about the local regularity (if positive) or irregularity (if negative) of the signal at the given point, being in fact an extension of the concept of differentiability (Turiel et al., 2008). Due to its connection with the theory of turbulent flows, it has been shown that the singularity exponents obtained from any ocean scalar delineate the streamlines of the flow. Details of the method is provided in the Appendix.

\section{Results and discussion}

\subsection{Surface structure of the Arctic Front}

The spatial distribution of the climatological (2002-2009) SST of the Norwegian Sea, shown in Fig. 3a, illustrates a typical example of the distribution of surface waters in the Norwegian Sea. The figure shows that the warmest waters are confined to the eastern Norwegian Sea, while the coldest waters are found in the Greenland Basin west of the Mohn Ridge. From a closer inspection, the comparatively large temperature gradient associated with the AF at the Mohn Ridge (Piechura and Walczowski, 1995) can be identified. This large temperature gradient over the Mohn Ridge is associated with the warm Atlantic Water in the Lofoten Basin and the colder Arctic Waters in the Greenland Basin. In addition to SST, we use remotely sensed winds to identify the ocean fronts in the Norwegian Sea, as has been done for parts of the global ocean (e.g. Song et al., 2006). Figure $3 \mathrm{~b}$ shows the spatial distribution of the climatology (2002-2009) of wind speed in the Norwegian Sea. Note that the choice of time-averaged fields assists in avoiding possible contamination of the wind field by the rapid evolution of weather patterns (Chelton et al., 2004). Comparison of Fig. 3a and b reveals stronger/weak winds over warm/cold waters. Even though shown for the first time in the Norwegian Sea, the increase/decrease in surface wind speed when it blows from cold/warm to warm/cold water is well-known, and the physical mechanism has been extensively studied (e.g. Friehe et al., 1991; Chelton et al., 2004; Song et al., 2006). The response of the surface wind to the temperature fronts has been studied on different timescales (monthly, Chelton et al., 2001; seasonal, O'Neill et al., 2003; and climatological, Chelton et al., 2004) especially in the western boundary currents. Stronger surface winds over warmer waters are due to efficient turbulent convection that transfers momentum down to the surface (Wallace et al., 1989). This process known as the momentum mixing mechanism destabilises air over warm water, and the increased turbulent mixing of momentum accelerates near-surface winds. Conversely, cold SST suppresses the momentum mixing, decouples the nearsurface wind from wind aloft, and decreases the near-surface wind. Another interesting feature seen in the wind field is the cold tongue of Arctic Water in the southern Norwegian Sea $\left(\sim 63^{\circ} \mathrm{N}, 8\right.$ to $4^{\circ} \mathrm{W}$; location 2 in Fig. 4 a). This cold tongue is caused by mixing of the water mass carried by the North Icelandic Irminger Current into the surrounding waters, mostly in the East Icelandic Current, which flows into the south-west Norwegian Sea, where it forms a cold tongue of Arctic character (Helland-Hansen and Nansen, 1909; Blindheim and Malmberg, 2005). Note that the main focus of the present study is to study the mean and variability of the AF. The SST-wind interaction over the AF revealed in this study warrants a detailed analysis and needs to be math- 
(a) SST

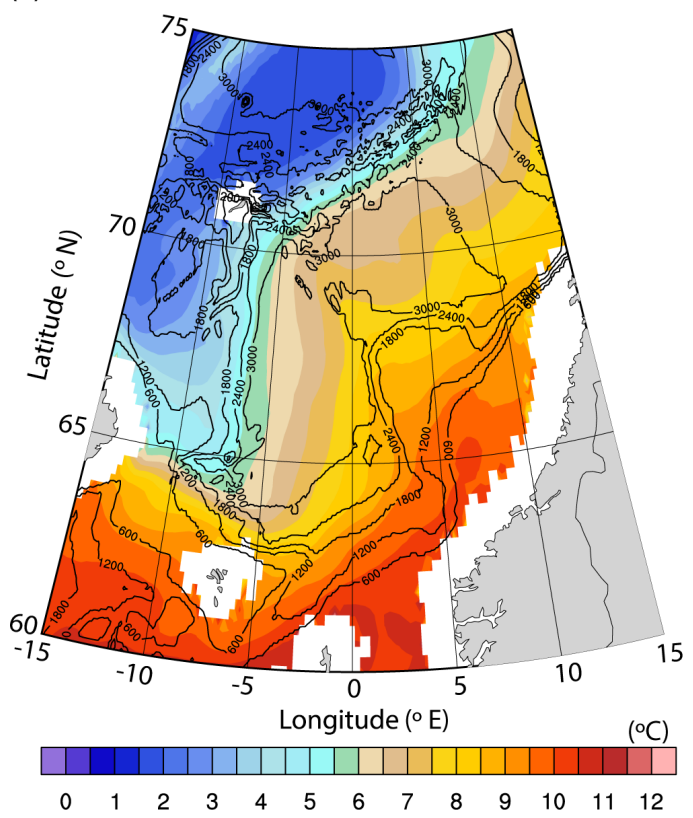

(b) Wind speed

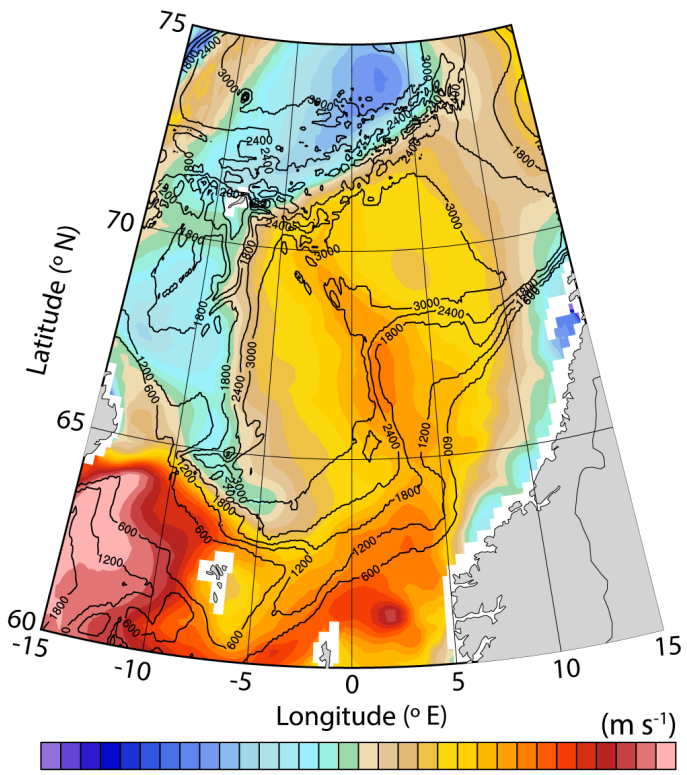

$\begin{array}{llllllll}7 & 7.27 .47 .67 .8 & 8 & 8.2 & 8.48 .68 .8 & 9 & 9.29 .49 .69 .8 & 10\end{array}$

Figure 3. Climatological mean (2002-2009) (a) AMSRE SST $\left({ }^{\circ} \mathrm{C}\right)$ and (b) QuikSCat wind speed (m s${ }^{-1}$ ). Black isobaths are drawn for every $600 \mathrm{~m}$.

ematically formulated, and hence is outside the scope of this study.

Singularity exponents estimated from these mean satellite SST and wind speed fields, as shown in Fig. 4, provide a clearer and more consistent picture of the AF in the Norwegian Sea compared to the original scalar fields. The AF in the Norwegian Sea are characterised by negative singularity exponents. Previous studies using singularity exponent analysis also found similar results in frontal regions (e.g. Fig. 5 in Turiel et al., 2008). Regarding the SST, regions with negative singularity exponents correspond to regions with higher irregularity, i.e. to grid points with stronger gradient variations (see Figs. 3a and 4a for SST) than the neighbouring grid points (sharp transition). On the other hand, regions with positive singularity exponents are those where the gradient variations are weak. The frontal region at the Mohn Ridge (location 1 in Fig. 4a) and that associated with the cold tongue and the Faroe Current in the south-west Norwegian Sea (location 2) are the locations where the AF is most prominent. The imprint of East Icelandic Current can also be seen in Fig. 4a (location 3). The AF extending north-east from the cold tongue region is locked between the 1800 and $2400 \mathrm{~m}$ depth contour (location 4). The signature of the AF at location 4 is not very prominent compared to locations 1 and 2. Further north over the Vøring Plateau (location 5), the continuation of the AF is not captured in our analysis. Note that this is also a region of intense mesoscale eddy activity. The tracks of mesoscale eddies in the region obtained from Raj et al. (2016; updated time series up to 2016) is shown in Fig. S2. The figure shows dominance of mesoscale eddies across the AF at locations
4 and 5, more prominent at location 5. Eddies are known to contribute significantly to the total oceanic heat and salt transport by advective trapping (Dong et al., 2014), stirring and mixing (Morrow and Le Traon, 2012). Most importantly they can play an important role in the cross-frontal transport (Dufour et al., 2015). Eddy-induced mixing and cross-frontal transport can reduce the sharp distinction of the water masses at the AF in location 5 compared to the other four. This can be a reason for the absence of the AF signature in the singularity exponents map. Quantifying the impact of mesoscale eddies on the AF requires dedicated effort and is outside the scope of our study.

All the above SST-related features are also portrayed in the map of singularity exponents of the wind speed (Fig. 4b), estimated from the mean satellite wind speed map (shown in Fig. 3b). Regions with the sharpest changes in wind speed are consistent with those found in the SST map (Fig. 4a). In other words, regions where SST is found to experience sharp changes correspond well to those with large changes in wind speed, thereby confirming the role of strong momentum mixing along the frontal regions. The analysis is repeated using other remote sensing data sets (WindSAT SST, AVHRR SST, WindSAT wind speed and AMSRE wind speed) in order to examine whether the ocean fronts in the Norwegian Sea can be retrieved irrespective of the satellite data and sensor used. Singularity analysis on these satellite SST and wind speed data sets also illustrates similar AF signatures to those seen in Fig. 4 (not shown). Hence it can be stated that the satellitederived wind speed and SST data reveal the frontal structure of the AF, irrespective of the sensor used. Thus, it is shown 
that singularity analysis is able to portray a much clearer representation of the $\mathrm{AF}$ compared to the original scalar fields.

\subsection{Subsurface structure of the Arctic Front}

Next, we assess the performance of the TOPAZ4 reanalysis results in reproducing the horizontal structure of the AF in the Norwegian Sea, using a longer period (1991-2015) than that of the satellite data (2002-2009). The surface signature of the AF estimated from TOPAZ4 SST output (Fig. 5a) agrees with that of the satellite SST data (Fig. 4a). As mentioned in Sect. 2.1, TOPAZ4 reanalysis assimilates measurements including along-track altimetry data, sea surface temperatures, sea ice concentrations and sea ice drift from satellites along with in situ temperature and salinity profiles. Hence, the similarities in Figs. 4a and 5a are not surprising, although not warranted due to the residual errors of assimilation. Nevertheless, the figures confirm that TOPAZ4 reanalysis data are able to reproduce the AF signature and indicates that the TOPAZ4 results can be used to study the subsurface part of the AF. Further analysis show that the horizontal structure of the AF in the deeper ocean is similar to the surface; most distinct along the Mohn Ridge and near the Faroe Current in the south-west Norwegian Sea (as shown by the TOPAZ4 potential temperature singularity exponent maps in Fig. 5b and c).

Next, in order to examine the seasonal variability of the AF in the Norwegian Sea, singularity analysis is applied to the seasonal climatologies of SST and potential temperature at $200 \mathrm{~m}$ (Fig. 6). The surface signature of AF is found to be stronger during winter (DJF; Fig. 6a), while the frontal signature is less evident during summer (JJA; Fig. 6b). These results agree with the analysis done using seasonal satellite SST data (not shown). Note that the analysis of the subsurface temperature fields (Fig. 6c and d) does not reproduce the seasonal variability of the surface frontal structure (Fig. 6a and b). Thus, it can be concluded that the seasonal variability of the frontal structure is limited to the surface and not found in the subsurface. This is likely to be associated with the surface heating of the ocean during summer that in turn reduces the surface horizontal temperature gradient, evidence of which is found as a thin layer of (upper $25 \mathrm{~m}$ ) low-temperature gradient near the surface during summer (Fig. 7c), which is not present in winter (Fig. 7b), that disconnects the subsurface signatures of the front from the surface.

The TOPAZ4 reanalysis, which successfully replicates the lateral variability of the AF (Figs. 5-6), is further used to investigate the vertical structure of the $\mathrm{AF}$ and its variability. The vertical structure of the AF is analysed using a simple horizontal gradient method. The main reason for using a simple horizontal gradient method to estimate the strength of the front is to compare our results with previous studies (e.g. Piechura and Walczowski, 1995; Lobb et al., 2003). Furthermore, for this analysis the focus area is limited to a single section (shown in Fig. 4a) taken across the Mohn Ridge, where a strong frontal signature is found in the singularity exponents maps (Figs. 4-6). Analysing the variability of the AF over the Mohn Ridge is also important due to its proximity to Jan Mayen Island, which is well-known to be an important breeding region inhabited by large colonies of seabirds. Although higher up in the food chain, the variability of the AF may have an influence on the birds through the impact on biology and fisheries of the region. A similar section was used by Piechura and Walczowski (1995), to study the AF across the Mohn Ridge using CTD data during the time period 1987-1993. Figure 7a, b and c show respectively the mean, winter and summer climatology of potential temperature along the vertical cross-section at the Mohn Ridge (location shown in Fig. 4a). To the east (left side of the figure), the figure shows the warm Atlantic Water residing in the Lofoten Basin, while the cold waters reside in the Greenland Sea (right side of the figure). Note that these results agree with those reported by Piechura and Walczowski (1995). The temperature gradient along the vertical section delimits the $\mathrm{AF}$ at the Mohn Ridge (Fig. 7d). The location of the core of the front along the section across the Mohn Ridge is marked as red in Fig. 4a. At the location of the AF, a temperature change of roughly $2^{\circ}$ can be noted from Fig. $7 \mathrm{a}$. The potential temperature gradient $\left(0.04^{\circ} \mathrm{C} \mathrm{km}^{-1}\right)$ across the core of the $\mathrm{AF}$ is comparable with those reported at other high-latitude frontal regions (Lobb et al., 2003). The AF extends from the surface down to $600 \mathrm{~m}$ depth with the core stretching over depths from 50 to $400 \mathrm{~m}$, as indicated by the strong potential temperature horizontal gradient areas (dark blue contours) in Fig. $7 d-f$. The frontal structure is well connected to the surface during winter (Fig. 7b and e), while in summer, the stratified layer of warm water at the surface (upper $25 \mathrm{~m}$ ) disconnects the AF deeper layers from the surface (Fig. 7c and f). The figures also show that there is no seasonal variability in the location of the core of the AF over the Mohn Ridge.

\subsection{Impact of large-scale atmospheric forcing on the Arctic Front}

The impact of the large-scale atmospheric forcing in the Norwegian Sea (Fig. 2) on the variability of the AF over the Mohn Ridge is investigated next using composite analysis on monthly TOPAZ4 data. For this, composite maps (Sect. 3.2) of the temperature across the Mohn Ridge during the positive and negative phases of the NAO, EAP and SCAN are produced and the gradient in mean temperature is estimated. The analysis shows that the location of the core of the AF along the Mohn Ridge is not influenced by the large-scale atmospheric variability (Figs. 8, S3). Here, the AF is defined as the region with the maximum in temperature gradient, a classical definition used to distinguish between two distinct water masses, in this case the Atlantic Water and the Arctic Waters. The non-variability in the location of the position of the AF further indicates that the location of the two water 
(a) SST

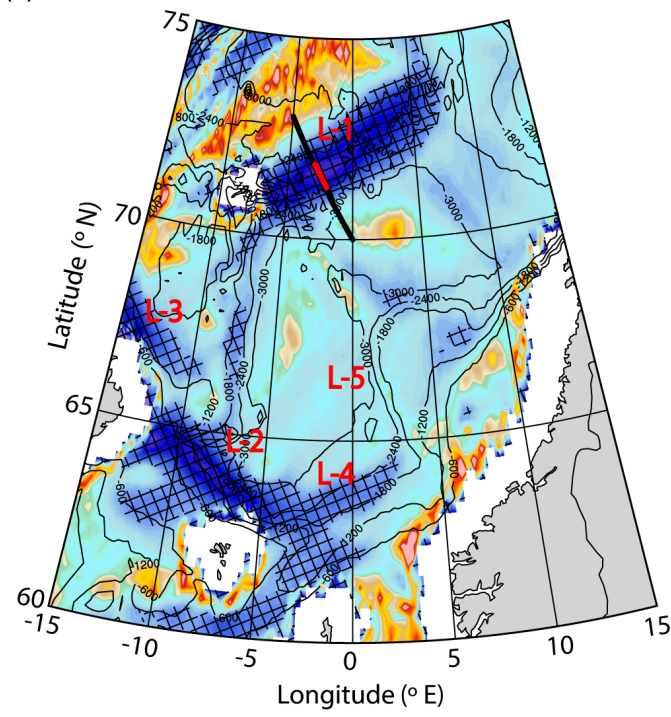

(b) Wind speed

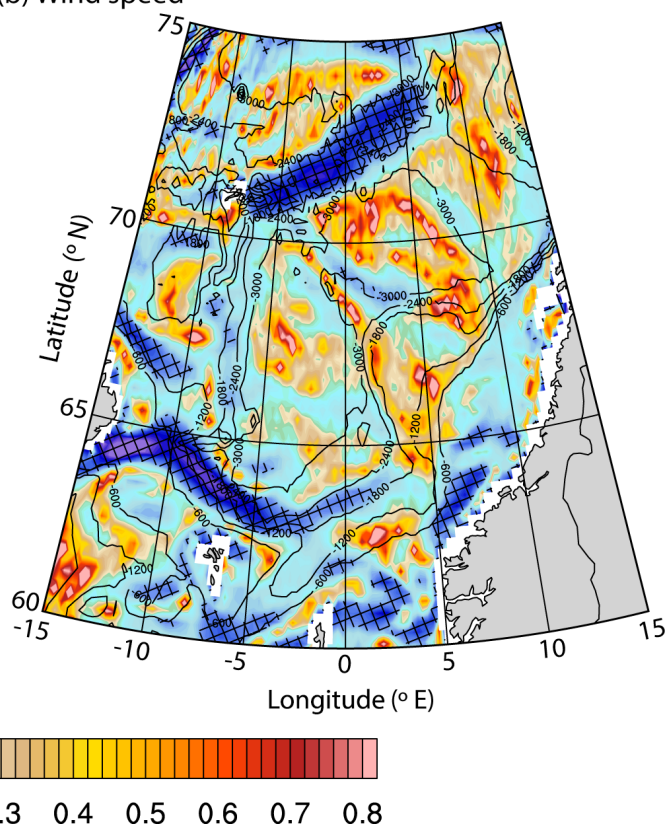

Figure 4. Singularity exponents estimated from the climatological mean (2002-2009) (a) AMSRE SST and (b) QuikSCat wind speed. Black isobaths are drawn for every $600 \mathrm{~m}$. In panel (a), the bold black line shows the location of the vertical section across the Mohn Ridge shown in Figs. 7, 8 and 10. The position of the core of the AF shown in Fig. 7 is marked as red over the bold black line. Locations 1, 2, 3, 4 and 5 are represented respectively by L-1, L-2, L-3, L-4 and L-5. Negative values are highlighted (black hatching).
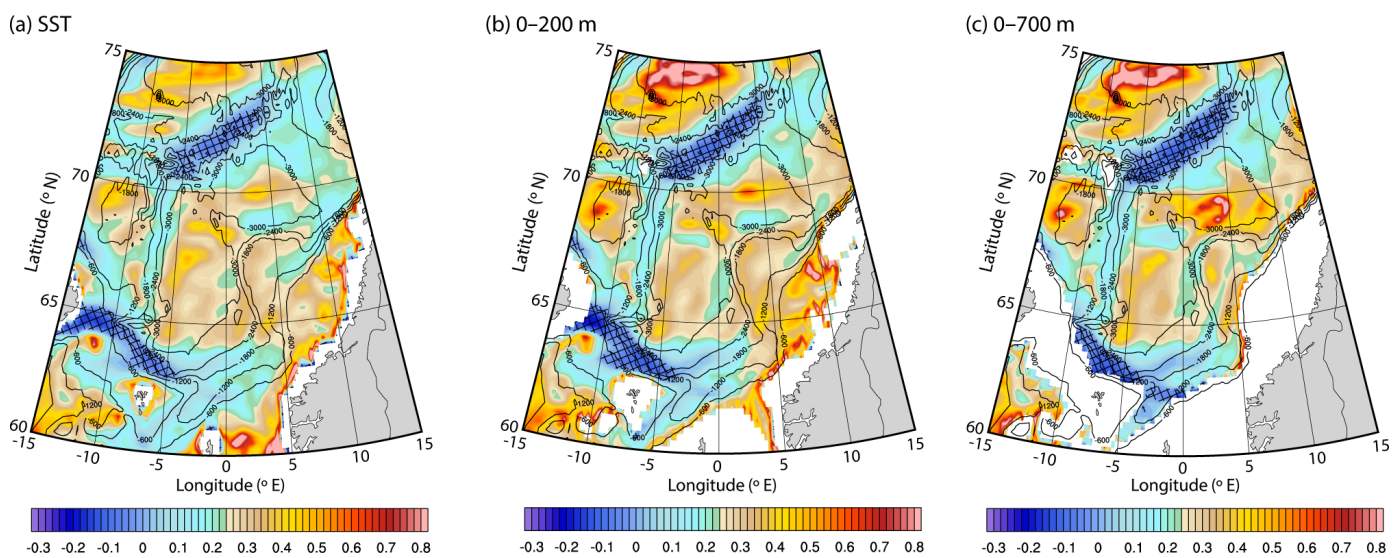

Figure 5. Singularity exponents estimated from TOPAZ (a) SST, (b) upper $200 \mathrm{~m}$ and (c) upper $700 \mathrm{~m}$ depth averaged potential temperature for the time period 1991-2015. Black isobaths are drawn for every $600 \mathrm{~m}$. Regions shallower than 200 and $700 \mathrm{~m}$ are masked respectively in panels (b) and (c). Negative values are highlighted (black hatching).

masses does not alter. However, Fig. $8 \mathrm{~b}$ shows a weakening of the AF during the negative phase of the NAO (NAO-). The weakening of the AF during NAO- is prominent in the upper $450 \mathrm{~m}$ depth (Fig. 8b). Compared to NAO, the second (EAP) and third (SCAN) modes of atmospheric variability in the Norwegian Sea do not show a major impact on the AF over the Mohn Ridge (Fig. S3). Further analysis thus only focuses on the two opposite phases of the NAO. The atmospheric circulation associated with the positive and negative phases of the NAO estimated using the ERA Interim surface winds is shown in Fig. 9. During NAO+, the composite map shows a distinct anomalous cyclonic pattern, centred on the Barents Sea Opening (Fig. 9a). In contrast, during NAO-, a weakened cyclonic circulation is found (shown as anomalous anticyclonic circulation) centred near the Mohn Ridge (Fig. 9b).

Next, we investigate the link between the atmospheric circulation during NAO- (Fig. 9b) and the weakening of the AF over the Mohn Ridge (Fig. 8b). We hypothesise that the impact of the NAO on ocean currents of the region may in- 
(a) SST

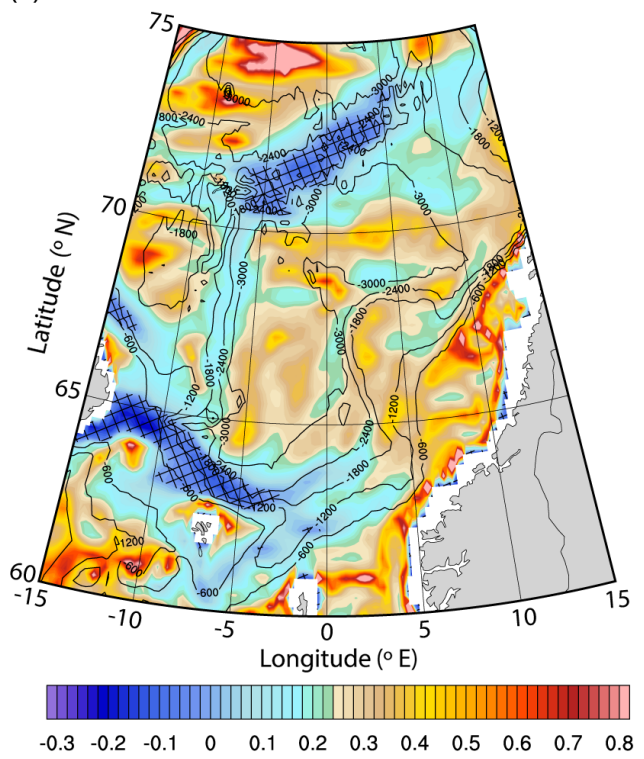

(c) $200 \mathrm{~m}$

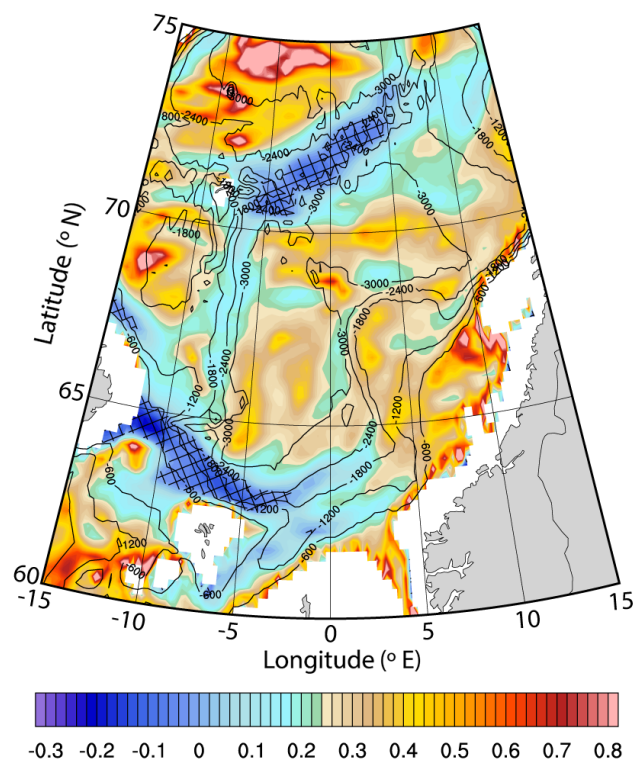

(b) SST

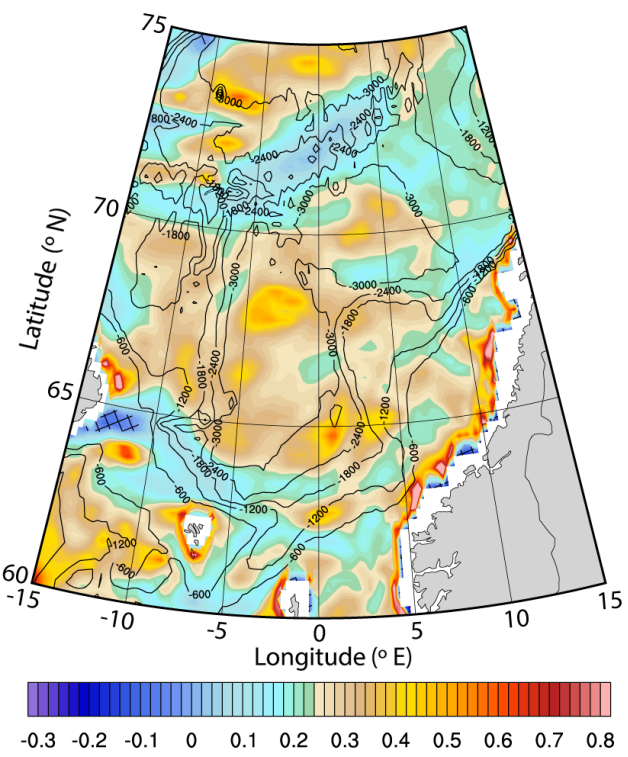

(d) $200 \mathrm{~m}$

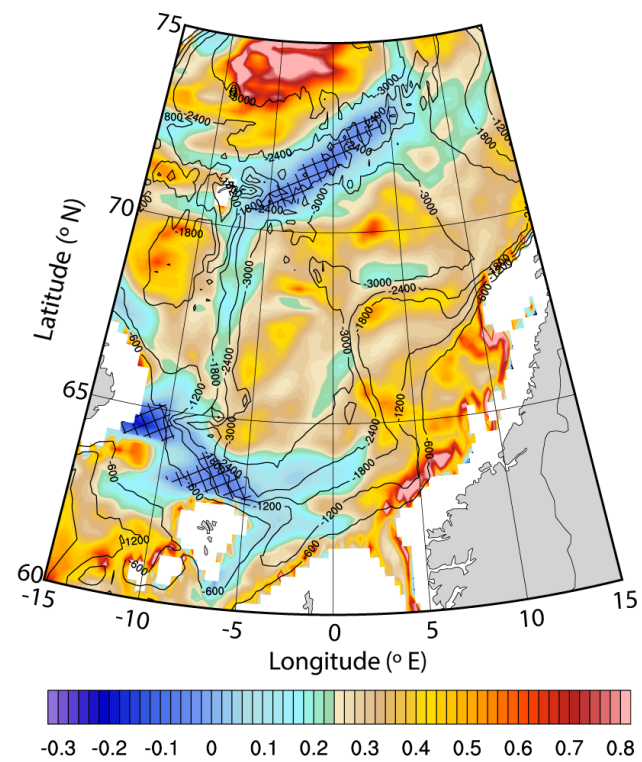

Figure 6. Singularity exponents estimated from TOPAZ (a-b) SST and (c-d) $200 \mathrm{~m}$ potential temperature for (a, c) winter (DJF) and (b, d) summer (JJA) for the time period 1991-2015. Negative values are highlighted (black hatching).

fluence the AF. Previous studies have reported the impact of the atmospheric variability on the ocean currents in the Norwegian Sea (e.g. Skagseth et al., 2008; Raj et al., 2018). Over the Mohn Ridge the NwAFC transports warm AW poleward. Note that although the vertical section over the Mohn Ridge is aligned almost perpendicularly to the AF, the maximum velocity component of the NwAFC and the gyre circulation are not necessarily perpendicular to the section, and hence cross-section velocities may not give a correct representation of the currents. Instead, the speed along the section can give a better representation of the currents, especially since the di- rection of the mean currents over the region does not change. Our results (Fig. 10) show that the core of the NwAFC over the Mohn Ridge is narrower and strengthened, especially at depths during $\mathrm{NAO}-$, while during $\mathrm{NAO}+$ it is broader and comparatively weaker in the subsurface (Fig. 10). The narrowing of the NwAFC associated with its strengthening during NAO- has resulted a shift of its core by about 20 $40 \mathrm{~km}$ away from the AF (Fig. 10b). Also, the strength of the NwAFC in the region where it gets narrower (AF indicated by dashed line in Fig. 10b) is also significantly differ- 

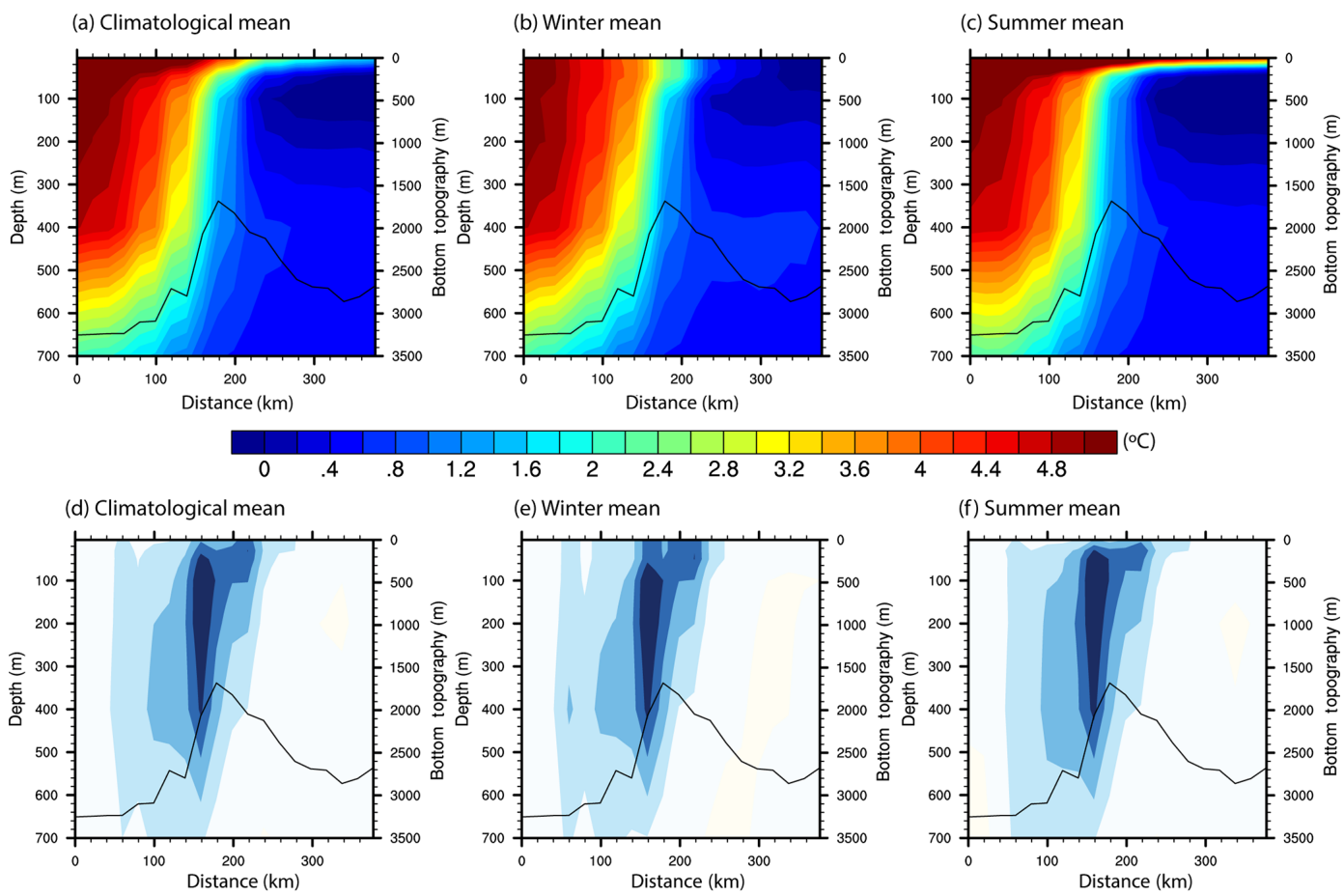

(e) Winter mean

(f) Summer mean

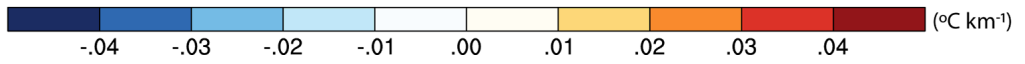

Figure 7. Temperature (a-c) and its horizontal gradient (d-f) along the hydrographic section across the Mohn Ridge. Climatological mean (a, d), winter (b, e) and summer (c, f). The bottom topography along the section is indicated by the black contour.
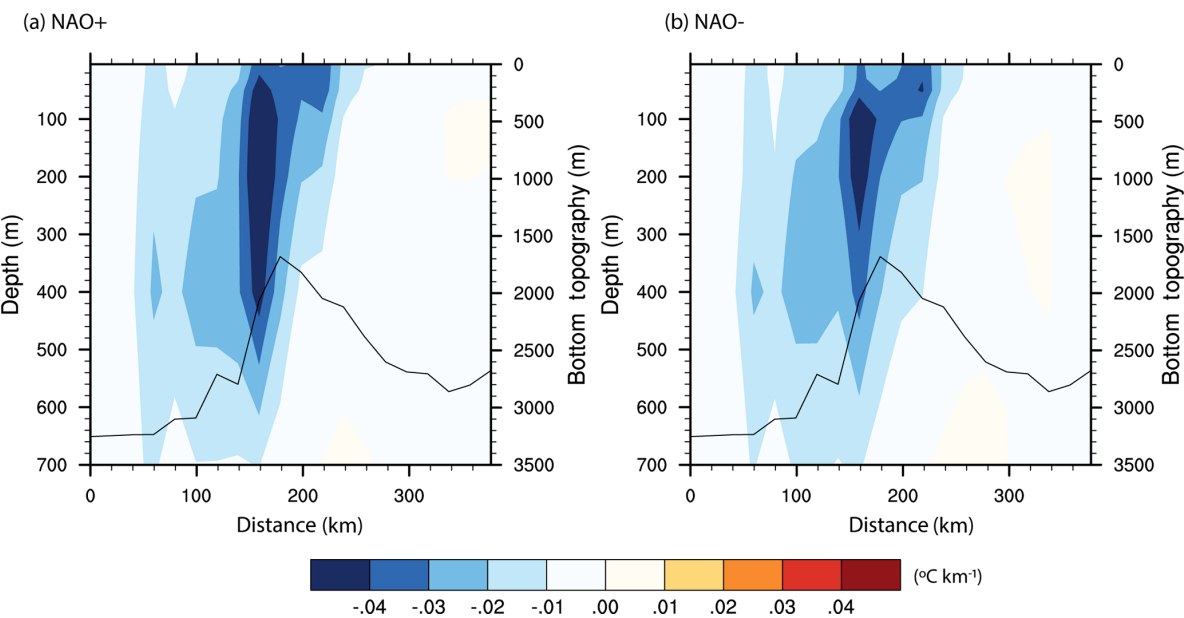

Figure 8. Gradient in the mean potential temperature $\left({ }^{\circ} \mathrm{C} \mathrm{km}^{-1}\right)$ along the hydrographic section across the Mohn Ridge during (a) NAO+ and (b) NAO-. The bottom topography along the section is indicated by the black contour.

ent (shown as stripped in Fig. 10b) from the climatological mean.

While the majority of previous studies reported the positive relation of the NAO with the speed of the NwASC (e.g. Skagseth and Orvik, 2002), our results show that the NwAFC behaves in an opposite way. One of the possible mechanisms by which a weakening in the cyclonic atmospheric circulation during NAO- (Fig. 9b) results in the strengthening of the NwAFC (Fig. 10b) is via its influence on the cyclonic gyre circulation of the Lofoten Basin. Near the Mohn Ridge, the cyclonic gyre circulation of the Lofoten Basin counter-propagates in comparison to the northward flow of the NwAFC (see Fig. 1). It has been argued that this counterpropagating part of the cyclonic gyre acts as a hindrance to the northward flow of the NwAFC, which in turn results in the weakening of the NwAFC (Orvik, 2004). In his study 
(a) NAO+

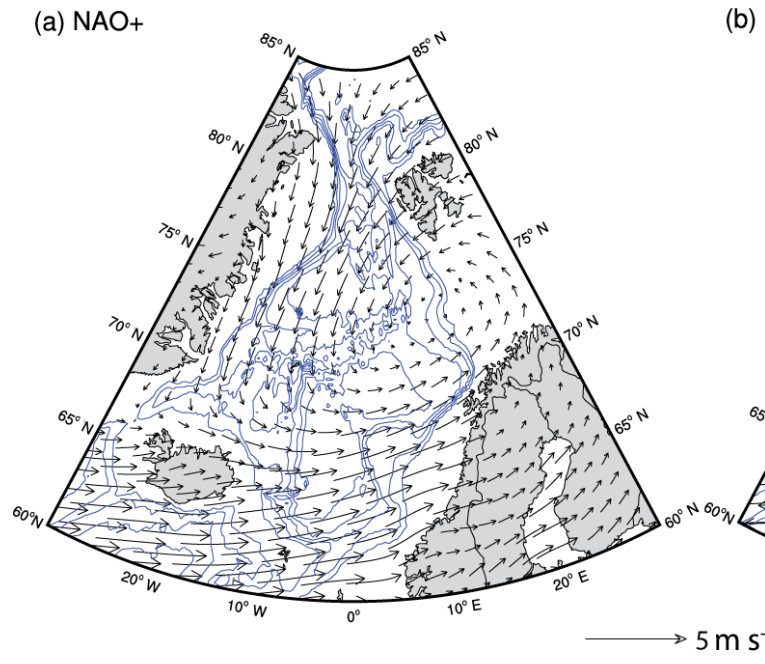

(b) NAO-

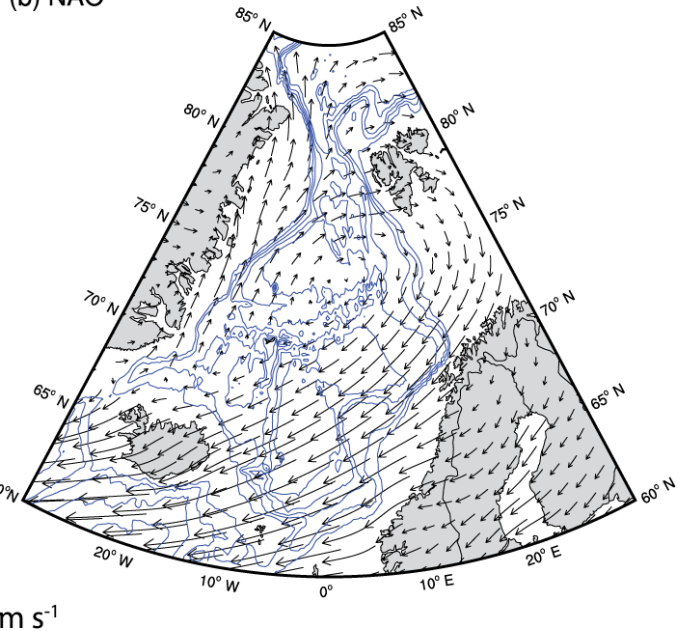

Figure 9. Composite map of anomalous winds (vectors), during (a) NAO+ and (b) NAO-. Anomalies are computed using monthly climatology fields for the period 1991-2015. Blue isobaths are drawn for every $600 \mathrm{~m}$. Only significant anomalies (10\% significance level) are shown.
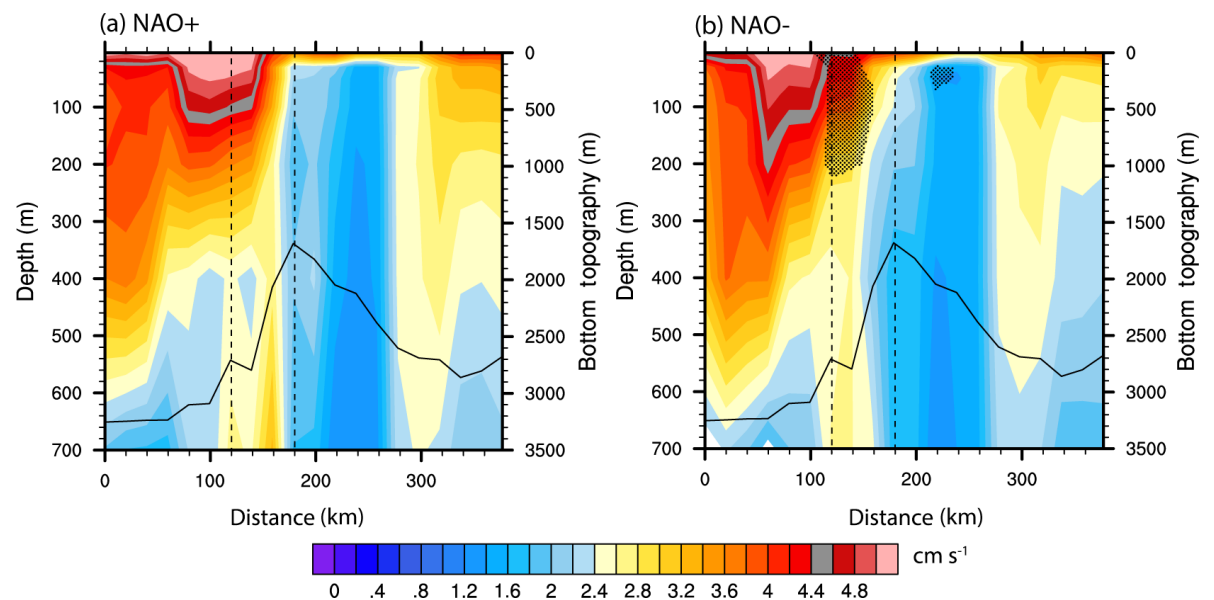

Figure 10. Composite of currents speed $\left(\mathrm{cm} \mathrm{s}^{-1}\right)$ along the hydrographic section across the Mohn Ridge during (a) NAO+ and (b) NAO- . The dashed vertical lines show the position of the core of the AF. Black stripped region in panel (b) indicates the region where the composite mean speed is significantly different from the climatological mean speed at $10 \%$ significance level.

using a reduced gravity model, Orvik (2004) showed that a weakening of the gyre circulation will result in the strengthening of the NwAFC as the hindrance is reduced. Regarding the link between NAO- and Lofoten Basin gyre circulation, we hypothesise that a weakening of the cyclonic atmospheric circulation during $\mathrm{NAO}-$ can result in the weakening of the Lofoten Basin gyre circulation. The evidence of this atmosphere-ocean interaction is shown in Fig. 11. The figure shows the composite of the monthly barotropic stream function (BSFD) data (estimated from depth-averaged currents) from the TOPAZ4 reanalysis, and exhibits the gyre circulations in the Lofoten Basin, the Greenland Sea and the Norwegian Basin. The negative values seen in Fig. 11a during $\mathrm{NAO}+$ indicate stronger cyclonic circulation. According to the figure, the cyclonic Lofoten Basin gyre circulation during
$\mathrm{NAO}+$ is found to be intensified. Conversely, a weakening of the Lofoten Basin gyre circulation is found during NAO(Fig. 11b; positive values indicate a weaker cyclonic circulation). This weakening in the gyre circulation of the Lofoten Basin during NAO- (Fig. 11b) can result in the strengthening of NwAFC (Fig. 10b) as there is less hindrance to the northward flow.

The discussion above explains the link between the variability in the atmospheric circulation during NAO- (Fig. 9b) and the strengthening and narrowing of the NwAFC over the Mohn Ridge (Fig. 10b). Associated with the strengthening and narrowing of the NwAFC during NAO-, our study also identified a shift $(20-40 \mathrm{~km})$ in the core of the NwAFC away from the core of the AF. A shift in the core of the NwAFC from the topographically trapped AF can result in the de- 


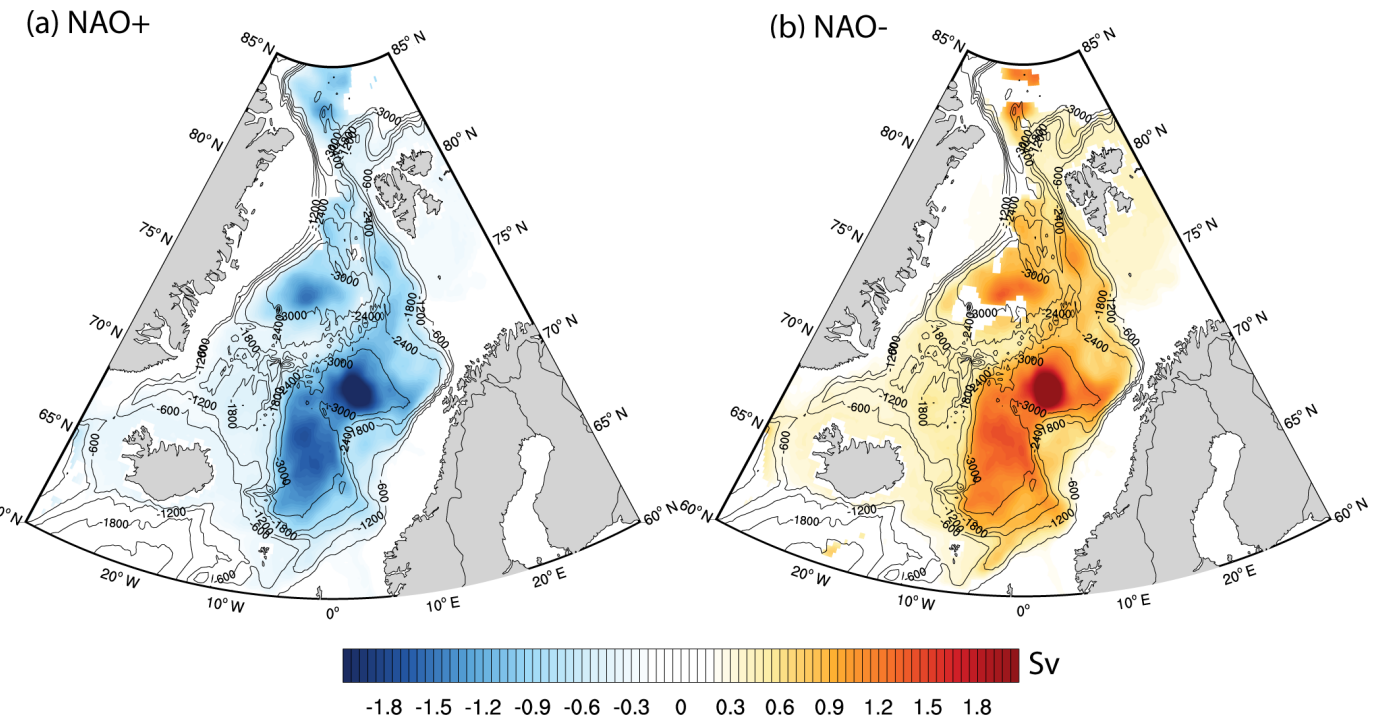

Figure 11. Composite map of anomalous BSFD, during (a) NAO+ and (b) NAO-. Black isobaths are drawn for every $600 \mathrm{~m}$. Anomalies are computed using monthly climatology fields for the period 1991-2015. Only significant anomalies (10\% significance level) are shown.

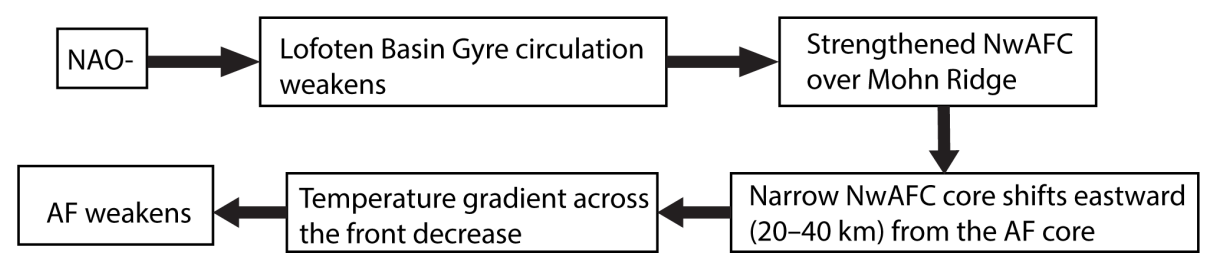

Figure 12. Graphical representation of the different processes associated with the weakening of the AF during NAO-.

crease in the temperature gradient across the front, in turn leading to the weakening of the front (Fig. 8b). A schematic illustration of the different processes connecting NAO- to a weakened AF as explained above is shown in Fig. 12. However, note that the physical mechanism explained in Fig. 12 may not be applicable to the variability of AF at location L2 in Fig. 4a, another location where the AF is found to be most prominent (Figs. 4-6). This is due to the fact that the circulation pattern over the Mohn Ridge is different compared to that at L2; i.e. while the gyre circulation in the Lofoten Basin is opposite the northward flow of the NwAFC over Mohn Ridge, the flow of the NwAFC at location L2 follows the direction of the gyre circulation of the region (Fig. 1). The impact of the NAO on the AF at location $\mathrm{L} 2$ needs to be analysed in detail since anomalous winds were found over the region during opposite phases of the NAO (Fig. 9). We recommend a separate study on the topic since it is outside the scope of this study.

\section{Summary}

Satellite-derived SST and wind speed data are good upperlevel proxies for the hydrographic signature of semipermanent ocean fronts across the Norwegian Sea. They re- veal the frontal structure of the AF, irrespective of the sensor used. The AF is found to be strongest over the Mohn Ridge and near the Iceland Faroe Plateau. The study shows evidence of active air-sea interaction along the AF. Compared to the original scalar fields (SST and wind speed), a more precise picture of the AF in the Norwegian Sea is obtained from their corresponding singularity exponents. The AF at the Mohn Ridge extends from the surface down to $600 \mathrm{~m}$ depth. The seasonal variability of the AF is limited to the surface and associated with the surface heating of the ocean during summer that reduces the horizontal surface temperature gradient. There is no seasonal variability in the location of the AF core over the Mohn Ridge. For the first time, the role of the three dominant atmospheric modes in the Norwegian Sea on the variability of the AF is investigated. Out of the three, only the NAO influences the AF along the Mohn Ridge. The study reveals a profound weakening of the AF over the Mohn Ridge during NAO-, which is further associated with the variability of the prevailing atmospheric circulation. A weakening of the cyclonic atmospheric circulation during NAO- weakens the deep gyre circulation of the Lofoten Basin, which in turn results in a strengthened and narrower NwAFC in opposite direction. The narrowing of the NwAFC causes its core to shift eastwards $(20-40 \mathrm{~km})$ from 
the core of the topographically trapped AF, which leads to a decreased temperature gradient across the front, and in turn to a weakening of the front.
Code and data availability. All data sets used in this study are freely available. TOPAZ model data are available via the CMEMS portal (http://marine.copernicus.eu/services-portfolio/ access-to-products/?option=com_csw\&view=details\&product_id= ARCTIC_REANALYSIS_PHYS_002_003, last access: November 2018; Xie et al., 2017). The satellite data sets used here are available at http://apdrc.soest.hawaii.edu. ERA interim data are available at https://apps.ecmwf.int/datasets/data/interim-full-moda/ levtype $=\mathrm{sfc} /$. The online toolbox used for the estimation of singularity exponents of the satellite and TOPAZ data are available at http://bec.icm.csic.es/CP34GUIWeb (free registration). 


\section{Appendix A: Singularity analysis}

In 1941, Kolmogorov (1941) introduced the concept of scale invariant dissipations. Turbulence is characterised by an infinite amount of degrees of freedom and thus it is impossible to fully characterise what happens at each element of the fluid. However, the large number of degrees of freedom allowed for a statistical approach, and thus turbulent flows could be characterised by effective quantities. What Kolmogorov proposed was that there is a simple relation between the energy dissipation at a scale $L$ and the energy dissipation at a smaller-scale $r$, as follows:

$\frac{\varepsilon_{r}}{\varepsilon_{L}}=\left(\frac{r}{L}\right)^{\beta}$,

where $\varepsilon_{r}$ is the dissipation at the scale $r$ and $\varepsilon_{L}$ is the dissipation at the larger-scale $L$. This relation was called "normal scaling" as it implies a simple distribution of energy across scales; in fact, it is sometimes referred to as linear scaling because Eq. (A1) implies that plot of the logarithm of $\varepsilon_{r}$ versus the logarithm of $r$ should be a straight line of slope $\beta$. It was soon realised that "normal scaling" was not frequent at all. Conversely the plots of the logarithm of the energy dissipation at scale $r$ versus the logarithm of $r$ generally showed a concave curve, the so-called "anomalous scaling", thus revealing that there was a much richer statistical interplay between the scales. Equation (A1) can be generalised in a stochastic way to account for that fact, namely

$\varepsilon_{r} \sim \eta_{\frac{r}{L}} \varepsilon_{L}$

where $\eta_{\frac{r}{L}}$ is a random stochastic variable which only depends on the ratio of scales $r$ and $L$, and the symbol $\sim$ means that both sides have identical statistical distribution. The variable $\eta_{\frac{r}{L}}$ is called the cascade variable, because it defines a cascade relation (its distribution for a change in scale $L$ to $r$ must be the same if we change first from scale $L$ to any intermediatescale $l$ and then from $l$ to $r$ ).

In 1985, Parisi and Frisch (1985) first introduced the concept of multifractals to explain that in fact the properties of cascade variables could be understood if we supposed that there is a hierarchy of fractal components $F_{\mathrm{h}}$, each one associated with a particular local dissipation exponent $h$, and such that the fractal dimensions of each fractal component could be related with the distribution of the cascade variables. There has been extensive literature by Turiel and colleagues explaining the connection between this microscopic behaviour (the local exponents $h$ ) and global statistical properties, which led to the introduction of singularity analysis. By means of singularity analysis we want to determine the local properties of scaling of the energy dissipation or any other scalar variable in a turbulent flow. To evaluate singularity analysis, we must proceed by applying continuous wavelet transforms to the variable under study (let us call it $\theta$ ), namely

$T_{\Psi}|\nabla \theta|(\boldsymbol{x}, r) \equiv \int d \boldsymbol{y} \frac{1}{r^{2}} \Psi\left(\frac{\boldsymbol{y}-\boldsymbol{x}}{r}\right)|\nabla \theta|(\boldsymbol{y})$,

where $r$ is the scale of observation and $\boldsymbol{x}$ is the point at which the wavelet is been applied. We apply the wavelet projection on the modulus of the gradient of the variable because it has been shown to be useful to remove long-range correlations and thus reveal the actual local behaviour of the function (Turiel et al., 2008). For turbulent fluids, according to Parisi and Frisch (1985) the cascade relation translates into the wavelet projection as

$T_{\Psi}|\nabla \theta|(\boldsymbol{x}, r) \propto r^{h(\boldsymbol{x})}$.

Therefore, a log- $\log$ regression of the wavelet projection versus the logarithm of the scale allows one to calculate the singularity exponent $h(\boldsymbol{x})$, which would be the slope of that regression. Something important to notice about singularity exponents is that they are unitless: they are dimensionless measurements of the local correlation of the gradient of the variable $\theta$ at the point $x$ with the same variable at the neighbouring points. Therefore, changes in the amplitude of the variable are irrelevant, as they just change the proportionality constant in Eq. (A4) that is not accounted for in the log-log regression because it only contributes to the intercept (and $h(\boldsymbol{x})$ is the slope of that regression). In fact, local changes in amplitude that change slowly enough across the area do not change the singularity exponents either. Singularity analysis is then more robust than other approaches as wavelet transform modulus maxima (WTMM), because it is not affected by those artefacts, and does not imply any particular condition on the geometry of the singularity fronts (WTMM require maxima points to be isolated); in addition, singularity analysis is in a close connection with the turbulent properties of the flow. The choice of the particular wavelet allows for better discrimination of the singularity exponents at the resolution scale; in this paper we have chosen the same as in Pont et al. (2013). 
Supplement. The supplement related to this article is available online at: https://doi.org/10.5194/os-15-1729-2019-supplement.

Author contributions. RPR initiated the collaboration and designed the outline of the paper. SC and RPR were instrumental in the data analysis. RPR, SC, LB, AT and MP contributed to the interpretation of results. RPR led the writing of the paper with significant contributions from all co-authors, at all stages of the paper.

Competing interests. The authors declare that they have no conflict of interest.

Special issue statement. This article is part of the special issue "The Copernicus Marine Environment Monitoring Service (CMEMS): scientific advances". It does not belong to a conference.

Acknowledgements. This research is funded by the Copernicus Arctic MFC services. We also acknowledge the CPU provided by the Norwegian supercomputing project Sigma2 (nn2993k) and the storage space (ns2993k). Author Sourav thanks the Nansen Scientific Society for the support. We also thank Richard. E. Danielson for his helpful suggestions.

Financial support. This research has been supported by the Copernicus Marine Services (grant no. 69).

Review statement. This paper was edited by Ananda Pascual and reviewed by Arthur Capet and two anonymous referees.

\section{References}

Aagaard, K., Swift, J. H., and Carmack, E. C.: Thermohaline circulation in the Arctic Mediterranean Seas, J. Geophys. Res., 90, 4833-4846, 1985.

Bakun, A.: Patterns in the Ocean: Ocean Processes and Marine Population Dynamics, California Sea Grant College System, San Diego, 1996.

Blindheim, J. and Ådlandsvik, B.: Episodic formation of intermediate water along the Greenland Sea Arctic Front, ICES CM1995/Mini:6, 11 pp. (mimeo), 1995.

Blindheim, J. and Malmberg, S.-A.: The mean sea level pressure gradient across the Denmark Strait as indicator of conditions in the North Icelandic Irminger Current, in: The Nordic Seas: An Integrated Perspective, AGU Geophysical Monograph (158), edited by: Drange, H., Dokken, T., Furevik, T., Gerdes, R., Berger, W., American Geophysical Union (AGU), Washington, 2005.

Blindheim, J. and Østerhus, S.: The Nordic Seas, main oceanographic features, in: The Nordic Seas: An Integrated Perspective. AGU Geophysical Monograph (158, pp. 11-38), edited by:
Drange, H., Dokken, T., Furevik, T., Gerdes, R., Berger, W., American Geophysical Union (AGU), Washington, 2005.

Blindheim, J. and Rey, F.: Water-mass formation and distribution in the Nordic Seas during the 1990s, J. Mar. Sci., 61, 846-863, 2004.

Cayula, J.-F. and Cornillon, P.: Edge detection algorithm for SST images, J. Atmos. Ocean. Tech., 9, 67-80, 1992.

Cayula, J.-F. and Cornillon, P.: Multi-image edge detection for SST images, J. Atmos. Ocean. Tech., 12, 821-829, 1995.

Chafik, L., Nilsen, J. E. Ø., and Dangendorf, S.: Impact of North Atlantic Teleconnection Patterns on Northern European Sea Level, J. Mar. Sci. Eng., 5, 43, https://doi.org/10.3390/jmse5030043, 2017.

Chatterjee, S., Raj, R. P., Bertino, L., Skagseth, Ø., Ravichandran, M., and Johannessen, O. M.: Role of Greenland Sea gyre circulation on Atlantic Water temperature variability in the Fram Strait, Geophys. Res. Lett., 45, 8399-8406, https://doi.org/10.1029/2018GL079174, 2018.

Chelton, D. B., Esbensen, S. K., Schlax, M. G., Thum, N., Freilich, M. H., Wentz, F. J., Gentemann, C. L., McPhaden, M. J., and Schopf, P. S.: Observations of coupling between surface wind stress and sea surface temperature in the Eastern Tropical Pacific, J. Climate, 14, 1479-1498, 2001.

Chelton, D. B., Schlax, M. G., Freilich, M. H., and Milliff, R. F.: Satellite measurements reveal persistent small-scale features in ocean winds, Science, 303, 978-983, 2004.

Comas-Bru, L. and McDermott, F.: Impacts of the EA and SCA patterns on the European twentieth century NAO-winter climate relationship, Q. J. Roy. Meteorol. Soc., 140, 354-363, 2013.

D'Asaro, E., Lee, C., Rainville, L., Harcourt, R., and Thomas, L.: Enhanced turbulence and energy dissipation at ocean fronts, Science, 332, 318-322, 2011.

Dee, D. P., Uppala, S. M., Simmons, A. J., Berrisford, P., Poli, P., Kobayashi, S., Andrae, U., Balmaseda, M. A., Balsamo, G., Bauer, P., Bechtold, P., Beljaars, A. C. M., van de Berg, L., Bidlot, J., Bormann, N., Delsol, C., Dragani, R., Fuentes, M., Geer, A. J., Haimberger, L., Healy, S. B., Hersbach, H., Hólm, E. V., Isaksen, L., Kållberg, P., Köhler, M., Matricardi, M., McNally, A. P., Monge-Sanz, B. M., Morcrette, J.-J., Park, B.-K., Peubey, C., de Rosnay, P., Tavolato, C., Thépaut, J.-N., and Vitart, F.: "The ERA-Interim Reanalysis: Configuration and Performance of the Data Assimilation System”, Q. J. Roy. Meteorol. Soc., 137, 553597, https://doi.org/10.1002/qj.828, 2011.

Dong, C., McWilliams, J. C., Liu, Y., Chen, D.: Global heat and salt transports by eddy movement, Nat. Commun., 5, 3294, https://doi.org/10.1038/ncomms4294, 2014.

Dufour, C. O., Griffies, S. M., de Souza, G. F., Frenger, I., Morrison, A. K., Palter, J. B., Sarmiento, J. L., Galbraith, E. D., Dunne, J. P., Anderson, W. G., and Slater, R. D.: Role of mesoscale eddies in cross-frontal transport of heat and biogeochemical tracers in the Southern Ocean, J. Phys. Oceanogr., 45, 3057-3081, https://doi.org/10.1175/JPO-D-14-0240.1, 2015.

Eldevik, T., Nilsen, J. E. Ø., Iovino, D., Olsson, K. A., Sand $\varnothing$, A. B., and Drange, H.: Observed sources and variability of Nordic seas overflow, Nat. Geosci., 2, 406-410, https://doi.org/10.1038/ngeo518, 2009.

Friehe, C. A., Shaw, W. J., Rogers, D. P., Davidson, K. L., Large, W. G., Stage, S. A., Crescenti, G. H., Khalsa, S. J. S., Greenhut, G. K., and Li, F.: Air-sea fluxes and surface layer turbulence around 
a sea surface temperature front, J. Geophys. Res., 96, 8593-8609, 1991.

Garcia-Olivares, A., Isern-Fontanet, J., and Garcia-Ladona, E.: Dispersion of passive tracers and finite-scale Lyapunov exponents in the Western Mediterranean Sea, Deep-Sea Res. Pt. I, 54, 253268, 2007.

Hannachi, A., Jolliffe, I. T., and Stephenson, D. B.: Empirical orthogonal functions and related techniques in atmospheric science: a review, Int. J. Climatol., 27, 1119-1152, 2007.

Helland-Hansen, B. and Nansen, F.: The Norwegian Sea: its physical oceanography based upon the Norwegian Research 19001904, Report on Norwegian Fishery and Marine Investigations, 2, 1909.

Holst, J. C., Røttingen, I., and Melle, W.: The herring, in: The Norwegian Sea Ecosystem, edited by: Skjoldal, H. R., Tapir Academic Press, Trondheim, Norway, 203-226, 2004.

Kolmogorov, A. N.: Dissipation of energy in a locally isotropic turbulence, Dokl. Akad. Nauk. SSSR 32, 16-18, 1941.

Lien, S. V., Hjøllo, S. S., Skogen, M. D., Svendsen, E., Wehde, H., Bertino, L., Counillon, F., Chevallier, M., and Garric, G.: An assessment of the added value from data assimilation on modelled Nordic Seas hydrography and ocean transports, Ocean Model., 99, 43-59, 2016.

Lin, W., Portabella, M., Stoffelen, A., Turiel, A., and Verhoef, A.: Rain identification in ASCAT winds using singularity analysis, IEEE Geosci. Remote Sens. Lett., 11, 1519-1523, https://doi.org/10.1109/LGRS.2014.2298095, 2014.

Lobb, J., Weaver, A. J., Carmack, E. C., and Ingram, R. G.: Structure and mixing across an Arctic/Atlantic front in northern Baffin Bay, Geophys. Res. Lett., 30, 1833, https://doi.org/10.1029/2003GL017755, 2003.

Mallat, S. and Huang, W. L.: Singularity detection and processing with wavelets, IEEE T. Inform. Theory., 38, 617-643, 1992.

Melle, W., Ellertsen, B., and Skjoldal, H. R.: Zooplankton: The link to higher trophic levels, in: the Norwegian Sea Ecosystem, 137202, Tapir Academic Press, Trondheim, 2004.

Moore, G. W. K., Renfrew, I. A., and Pickart, R. S.: Multidecadal Mobility of the North Atlantic Oscillation, J. Climate, 26, 24532466, 2012.

Mork, K. A. and Skagseth, Ø.: A quantitative description of the Norwegian Atlantic Current by combining altimetry and hydrography, Ocean Sci., 6, 901-911, https://doi.org/10.5194/os-6-9012010, 2010

Morrow, R. and Le Traon, P.-Y.: Recent advances in observing mesoscale ocean dynamics with satellite altimetry, Adv. Spa. Res., 50, 1062-1076, 2012.

Nilsen, J. E. Ø. and Nilsen, F.: The Atlantic Water Flow along the Vøring Plateau: Detecting Front Structures in Oceanic Station Time Series, Deep-Sea Res., Pt. I, 54, 297-319, https://doi.org/10.1016/j.dsr.2006.12.012, 2007.

Norway Ministry of Environment: Integrated Management of the Marine Environment of the Norwegian Sea., Report No. 37 to the Storting, 1-151, 2008-2009.

O'Neill, L. W., Chelton, D. B., and Esbensen, S. K.: Observations of SST-induced perturbations of the wind stress field over the Southern Ocean on seasonal timescales., J. Climate, 16, 2340 2354, https://doi.org/10.1175/2780.1, 2003.

Orvik, K. A.: The deepening of the Atlantic water in the Lofoten Basin of the Norwegian Sea, demonstrated by using an active reduced gravity model, Geophys. Res. Lett., 31, L01306, https://doi.org/10.1029/2003GL018687, 2004.

Orvik, K. A. and Niiler. P.: Major pathways of Atlantic water in the northern North Atlantic and Nordic Seas toward Arctic, Geophys. Res. Lett., 29, 1896, https://doi.org/10.1029/2002GL015002, 2002.

Orvik, K. A. and Skagseth, Ø.: Monitoring the Norwegian Atlantic slope current using a single moored current meter, Cont. Shelf Res., 23, 159-176, 2003.

Orvik, K. A., Skagseth, Ø., and Mork. M.: Atlantic inflow to the Nordic Seas. Current structure and volume fluxes from moored current meters, VM-ADCM and SeasSoar-CTD observations, Deep-Sea Res. Pt. I, 48, 937-957, 2001.

Parisi. G. and Frisch, U.: On the singularity structure of fully developed turbulence, in: Turbulence and Predictability in Geophysical Fluid Dynamics, Proc. Intl. School of Physics E. Fermi, 84 87, edited by: Ghil, M., Benzi, R., and Parisi, G., North-Holland, New York, 1985.

Piechura. J. and Walczowski, W.: The Arctic Front: structure and dynamics, Oceanologia, 37, 47-73, 1995.

Pont, O., Turiel, A. and Yahia, H.: Singularity analysis of digital signals through the evaluation of their unpredictable point manifold, Int.1 J. Comput. Math., 90, 1693-1707, 2013.

Portabella, M., Stoffelen, A., Lin, W., Turiel, A., Verhoef, A., Verspeek, J., and Ballabrera-Poy, J.: Rain effects on ASCAT retrieved winds: towards an improved quality control, IEEE Geosci. Remote Sens. Lett., 50, 2495-2506, https://doi.org/10.1109/TGRS.2012.2185933, 2012.

Poulain, P. M., Warn-Varnas, A., and Niiler, P. P.: Near-surface circulation of the Nordic seas as measured by Lagrangian drifters, J. Geophys. Res., 101, 237-258, 1996.

Raj, R. P., Chafik, L., Nilsen, J. E. Ø., Eldevik, T., and Halo, I.: The Lofoten vortex of the Nordic Seas, Deep-Sea Res. Pt. I, 96, 1-14, https://doi.org/10.1016/j.dsr.2014.10.011, 2015.

Raj, R. P., Johannessen, J. A., Eldevik, T., Nilsen, J. E. $\varnothing$. , and Halo, I.: Quantifying Mesoscale Eddies of the Lofoten Basin, J. Geophys. Res.-Oceans, 121, 4503-4521, https://doi.org/10.1002/2016JC011637, 2016.

Raj, R. P., Nilsen, J. E. Ø., Johannessen, J. A., Furevik, T., Andersen, O. B., Bertino, L.: Quantifying Atlantic Water transport to the Nordic Seas by remote sensing, Remote Sens. Environ., 216, 758-769, https://doi.org/10.1016/j.rse.2018.04.055, 2018.

Skagseth, $\varnothing$. and Orvik, K. A.: Identifying fluctuations in the Norwegian Atlantic Slope Current by means of empirical orthogonal functions, Cont. Shelf Res., 22, 547-563, 2002.

Skagseth, Ø., Furevik, T., Ingvaldsen, R., Loeng, H., Mork, K. A., Orvik, K. A., and Ozhigin, V.: Volume and heat transports to the Arctic Ocean via the Norwegian and Barents Seas, in: Arctic Subarctic Ocean Fluxes, edited by: Dickson, R., Meincke, J., and Rhines, P., Springer Verlag, the Netherlands, 25-64, 2008.

Snedecor, G. W. and Cochran, W. G.: Statistical Methods, Eight Edition, Iowa State University Press, Ames, Lowa, 1989.

Song, Q., Cornillon, P., and Hara, T.: Surface wind response to oceanic fronts, J. Geophys. Res., 111, C12006, https://doi.org/10.1029/2006JC003680, 2006.

Swift, J. H.: The arctic waters, in: The Nordic Seas, edited by: Hurdle, B. G., Springer, Berlin, 1986. 
Swift, J. H. and Aagaard, K.: Seasonal transitions and water mass formation in the Iceland and Greenland Seas, Deep-Sea Res., 28A, 1107-1129, 1981.

Turiel, A., Sole, J., Nieves, V., Ballabrera-Poy, J., and GarciaLadona, E.: Tracking oceanic currents by singularity analysis of Micro-Wave Sea Surface Temperature images, Remote Sens. Environ., 112, 2246-2260, 2008.

Turiel, A., Nieves, V., Garcia-Ladona, E., Font, J., Rio, M.-H., and Larnicol, G.: The multifractal structure of satellite sea surface temperature maps can be used to obtain global maps of streamlines, Ocean Sci., 5, 447-460, https://doi.org/10.5194/os-5-4472009, 2009.

Umbert, M., Guimbard, S., Lagerloef, G., Thompson, L., Portabella, M., Ballabrera-Poy, J., and Turiel, A.: Detecting the surface salinity signature of Gulf Stream cold-core rings in Aquarius synergistic products, J. Geophys. Res.-Oceans, 120, 859-874, https://doi.org/10.1002/2014JC010466, 2015.
Walczowski, W. and Piechura, J.: New evidence of warming propagating toward the Arctic Ocean, Geophys. Res. Lett., 33, L12601. https://doi.org/10.1029/2006GL025872, 2006.

Wallace, J. M., Mitchell, T. P., and Deser, C.: The influence of sea surface temperature on surface wind in the eastern equatorial $\mathrm{Pa}-$ cific: seasonal and interannual variability, J. Climate, 2, 1492 1499, 1989.

Xie, J., Bertino, L., Counillon, F., Lisæter, K. A., and Sakov, P.: Quality assessment of the TOPAZ4 reanalysis in the Arctic over the period 1991-2013, Ocean Sci., 13, 123-144, https://doi.org/10.5194/os-13-123-2017, 2017. 